ORIGINAL ARTICLE

\title{
Cardiocirculatory and metabolic responses at different walking intensities
}

\author{
M Schwarz, A Urhausen, L Schwarz, T Meyer, W Kindermann
}

Br J Sports Med 2006;40:64-67. doi: 10.1136/bjsm.2005.020198

See end of article for authors' affiliations

.....................

Correspondence to: Dr Schwarz, Institute of Sports and Preventive Medicine, University of Saarland, Saarbrücken, Germany; mschwarz@mx. uni-saarland.de

Accepted 6 June 2005

\begin{abstract}
Objectives: Although walking is a common physical activity, scientifically based training guidelines using standardised tests have not been established. Therefore this explorative study investigated the cardiovascular and metabolic load resulting from different walking intensities derived from maximal velocity $\left(V_{\max }\right)$ during an incremental treadmill walking test.

Methods: Oxygen uptake, heart rate (HR), blood concentrations of lactate and catecholamines, and rating of perceived exertion were recorded in 16 recreational athletes (mean (SD) age 53 (9) years) during three 30 minute walking trials at $70 \%, 80 \%$, and $90 \%$ of $\mathrm{V}_{\max }\left(\mathrm{V}_{70}, \mathrm{~V}_{80}\right.$, and $\left.\mathrm{V}_{90}\right)$ attained during an incremental treadmill walking test.

Results: Mean (SD) oxygen uptake was $18.2(2.3), 22.3(3.1)$, and $29.3(5.0) \mathrm{ml} / \mathrm{min} / \mathrm{kg}$ at $\mathrm{V}_{70}, \mathrm{~V}_{80}$, and $\mathrm{V}_{90}$ respectively $(p<0.001)$. $\mathrm{V}_{70}$ led to a mean HR of 110 (9) beats $/ \mathrm{min}\left(66 \% \mathrm{HR}_{\text {max }}\right), \mathrm{V}_{80}$ to 124 (9) beats $/$ min $\left(75 \% \mathrm{HR}_{\max }\right)$, and $\mathrm{V}_{90}$ to $152(13)$ beats $/$ min $\left(93 \% \mathrm{HR}_{\max }\right)(\mathrm{p}<0.001)$. Mean (SD) lactate concentrations were $1.1(0.2), 1.8(0.6)$, and $3.9(2.0) \mathrm{mmol} / \mathrm{l}$ at $\mathrm{V}_{70}, \mathrm{~V}_{80}$, and $\mathrm{V}_{90}$ respectively $(p<0.001)$. There were no significant differences between catecholamine concentrations at the different intensities. Rating of perceived exertion was 10 (2) at $\mathrm{V}_{70}, 12$ (2) at $\mathrm{V}_{80}$, and 15 (2) at $\mathrm{V}_{90}$. Twelve subjects reported muscular complaints during exercise at $\mathrm{V}_{90}$ but not at $\mathrm{V}_{70}$ and $\mathrm{V}_{80}$.

Conclusions: Intensity and heart rate prescriptions for walking training can be derived from an incremental treadmill walking test. The cardiovascular and metabolic reactions observed suggest that $\mathrm{V}_{80}$ is the most efficient workload for training in recreational athletes. Further studies are needed to confirm these findings.
\end{abstract}

$\mathrm{O}$ ver the last few decades, walking has been established as one form of endurance training for preventive purposes. Sufficient training effects with little risk of overstrain have been suggested..$^{1-4}$ Data on appropriate training intensities for walking vary in the literature, and published test procedures only partly allow training recommendations to be derived. With regard to intensity, many authors refer to maximal heart rate or maximal oxygen uptake. $^{5-7}$ For efficient cardiocirculatory training, the American College of Sports Medicine (ACSM) recommends $55 / 65-90 \%$ of maximal heart rate $\left(\mathrm{HR}_{\max }\right)$ or $40 / 50-85 \%$ of maximal oxygen uptake reserve $\left(\mathrm{VO}_{2 \mathrm{R}}\right)$ or $\mathrm{HR}_{\max }$ reserve $\left(\mathrm{HR}_{\mathrm{R}}\right) .^{8}$ However, approaches that use an incremental treadmill walking test (ITWT) as the basis for individual training recommendations are rare. ${ }^{9-11}$

The purpose of this study was to check whether an ITWT is applicable for the derivation of individual training recommendations. A secondary aim was to investigate if walking allows middle aged people to reach sufficient training intensity at comfortable speeds.

\section{METHODS}

This study was approved by the institution's review board and complies with the Declaration of Helsinki. Each participant gave written informed consent.

\section{Subjects}

Sixteen healthy subjects ( 10 men, six women) took part in the study. Their mean (SD) age was 53 (9) years, height 169 (8) $\mathrm{cm}$, and weight 67 (11) kg. They were familiar with the walking technique and had been participating in recreational sport for an average of 34 months. Mean (SD) $\mathrm{P}_{\max }$ obtained from an incremental cycling test was $2.6(0.6) \mathrm{W} / \mathrm{kg}$.

\section{Study design}

Firstly, all subjects had a clinical and laboratory routine examination and performed an incremental cycling test to rule out any health risks. Two to seven days later an ITWT was conducted followed by three walking tests at constant velocities: $70 \%, 80 \%$, and $90 \%$ of the maximal velocity $\left(\mathrm{V}_{\max }\right)$ obtained during the ITWT. Figure 1 shows the course of the study. The test period ranged between two and four weeks for each subject. The participants were told to neither change their normal training load during the study nor perform intensive or prolonged physical exercise on the day before the tests.

\section{ITWT}

One ITWT was performed for training purposes two to seven days before the second ITWT which served as the basis for the later tests of constant velocity. Starting at $4.3 \mathrm{~km} / \mathrm{h}$, the velocity was increased by $0.7 \mathrm{~km} / \mathrm{h}$ every three minutes until exhaustion or $\mathrm{V}_{\max }$ was reached with the appropriate walking technique (no race walking or running). The test was carried out without treadmill inclination to simulate as close as possible walking in the field. After two to seven days, a second identical ITWT was performed. During these tests, HR was measured and recorded continuously with a portable device (Accurex-Plus; Polar, Kempele, Finland). For the determination of the blood lactate concentration (Super GL; Greiner, Flacht, Germany), capillary blood was taken from the hyperaemised earlobe at rest and after each stage during a break of about 20 seconds. From the lactate curve, the individual anaerobic threshold (IAT) was determined by the

Abbreviations: HR, heart rate; IAT, individual anaerobic threshold; ITWT, incremental treadmill walking test; RPE, rating of perceived exertion; $\mathrm{VO}_{2}$, oxygen uptake 


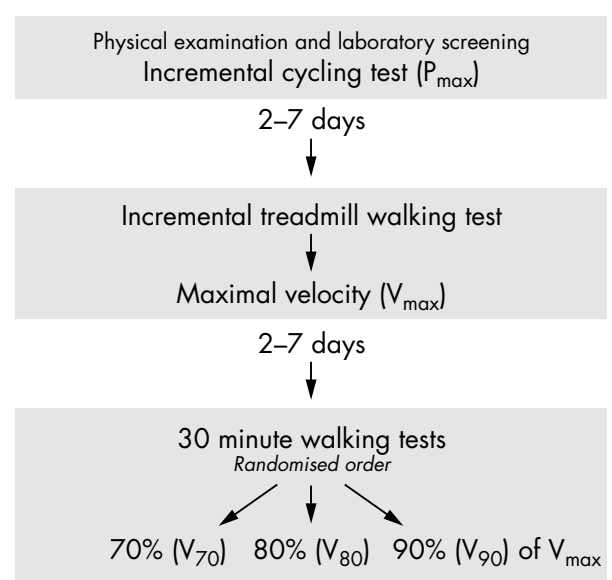

Figure 1 Overview of the study design.

method of Hagberg and Coyle, ${ }^{12}$ which was evaluated with race walkers. For the radioenzymatic determination of catecholamines $^{13}$ before and immediately after exercise, $300 \mu \mathrm{l}$ arterialised capillary blood was taken from the hyperaemized earlobe. In addition, gas exchange parameters (Meta-Max; Cortex, Leipzig, Germany) were continuously measured, and the rating of perceived exertion (RPE) recorded. ${ }^{14}$

With reference to $\mathrm{V}_{\max }$ individual intensities for three constant velocity exercises were determined $(70 \%, 80 \%$, and $90 \%$ of $\mathrm{V}_{\max }=\mathrm{V}_{70}, \mathrm{~V}_{80}$, and $\mathrm{V}_{90}$ ).

\section{Walking endurance exercises}

The subjects walked at the three intensities $\left(\mathrm{V}_{70}, \mathrm{~V}_{80}\right.$, and $\mathrm{V}_{90}$ ) on the same treadmill for 30 minutes in random order. Before the 30 minute exercise, each subject walked for three minutes at $V_{70}$ to warm up. During the exercise and for three minutes after it had finished, $\mathrm{HR}$ and oxygen uptake $\left(\mathrm{VO}_{2}\right)$ were continuously measured. With reference to $\mathrm{VO}_{2}$ and respiratory exchange ratio, energy output was calculated; $3.5 \mathrm{ml} / \mathrm{min} / \mathrm{kg}$ was considered to be 1 MET. Capillary samples for determination of lactate and catecholamine as well as the recording of RPE were carried out after 10 and 20 minutes of exercise during a 30 second break. Technical abnormalities and physical complaints were only recorded; no quantification was performed.

\section{Statistical analysis}

After normal distribution of data had been confirmed with the Kolmogoroff-Smirnov test, descriptive statistical analysis was performed; mean (SD) values were calculated. In the case of normally distributed data, a two factorial (intensity and time) analysis of variance was performed. The Scheffé test was used for post hoc comparisons. For ordinally scaled values (RPE), calculations were performed by non-para-

Table 1 Results from the incremental treadmill walking test

\begin{tabular}{lll}
\hline Variable & Max & IAT \\
\hline Velocity $(\mathrm{km} / \mathrm{h})$ & $8.3(0.6)$ & $6.9(0.6)\left(83 \% \mathrm{~V}_{\text {max }}\right)$ \\
Heart rate $(\mathrm{beats} / \mathrm{min})$ & $166(14)$ & $131(14)$ \\
Lactate $(\mathrm{mmol} / \mathrm{l})$ & $6.1(1.8)$ & $2.0(0.3)$ \\
Vo $_{2} \mathrm{MAX}(\mathrm{ml} / \mathrm{min} / \mathrm{kg})$ & $33.2(5.1)$ & $23.4(4.8)$ \\
Energy cost $(\mathrm{kJ} / \mathrm{min})$ & $46.7(7.1)$ & $32.9(6.8)$ \\
MET & $9.5(1.5)$ & $6.7(1.4)$ \\
\hline
\end{tabular}

Values are maximal performance (Max) and individual anaerobic threshold (IAT) during walking and are expressed as mean (SD) $(n=16)$.

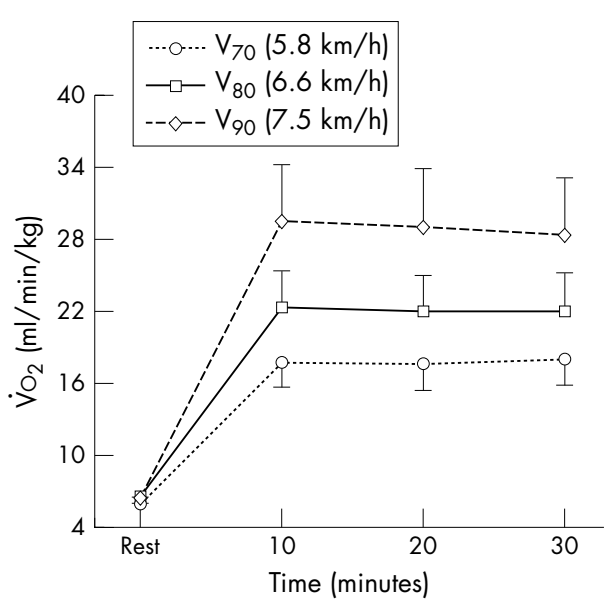

Figure 2 Oxygen uptake $\left(\mathrm{VO}_{2}\right)$ during the 30 minute walking trials at $70 \%, 80 \%$, and $90 \%$ of the maximal velocity obtained in the incremental treadmill walking test $\left(V_{70}, V_{80}\right.$, and $\left.V_{90}\right)$. Values are mean (SD) $(n=$ 16). All three values at each time point are significantly different from each other $(p<0.001)$.

metric procedures (rank correlation according to Spearman). The significance level for the $\alpha$ error was set at $\mathrm{p}<0.05$.

\section{RESULTS}

\section{ITWT}

During the ITWT, the subjects reached a mean (SD) $\mathrm{V}_{\max }$ of $8.3(0.6) \mathrm{km} / \mathrm{h}$, and a mean (SD) $\mathrm{VO}_{2} \mathrm{MAX}$ of $33.2(5.1) \mathrm{ml} /$ $\mathrm{min} / \mathrm{kg}$. Table 1 gives the ITWT results.

\section{Walking trials}

Oxygen uptake

The subjects reached a $\mathrm{VO}_{2}$ of 18.2 (2.3) $\mathrm{ml} / \mathrm{min} / \mathrm{kg}(55 \%$ $\left.\mathrm{VO}_{2} \mathrm{MAX}\right)$ at $\mathrm{V}_{70}, 22.3(3.1) \mathrm{ml} / \mathrm{min} / \mathrm{kg}$ at $\mathrm{V}_{80}\left(67 \% \mathrm{VO}_{2} \mathrm{MAX}\right)$, and $29.3(5.0) \mathrm{ml} / \mathrm{min} / \mathrm{kg}$ at $\mathrm{V}_{90}\left(88 \% \mathrm{VO}_{2} \mathrm{MAX}\right)$. There was a significant effect of intensity on $\mathrm{VO}_{2}$. Figure 2 gives the results from post hoc testing. At $\mathrm{V}_{80}, \mathrm{~V}_{90-}$, and $\mathrm{V}_{\text {IAT }}$ all subjects were above $60 \% \mathrm{VO}_{2} \mathrm{MAX}$.

\section{$H R$}

Mean HR reached 110 (9) beats/min during $\mathrm{V}_{70}\left(66 \% \mathrm{HR}_{\max }\right)$, 124 (9) beats/min during $\mathrm{V}_{80}\left(75 \% \mathrm{HR}_{\max }\right)$, and 152 (13) beats/min during $\mathrm{V}_{90}\left(93 \% \mathrm{HR}_{\max }\right)$ (fig 3$)$. During $\mathrm{V}_{80}$ and $\mathrm{V}_{90}$ all subjects were above $65 \% \mathrm{HR}_{\max }$. HR during the $80 \%$ endurance exercise was significantly $(\mathrm{p}<0.05)$ lower than HR at IAT (131 (14) beats/min, $79 \% \mathrm{HR}_{\max }$ ). There was a significant effect of intensity on HR. Figure 3 shows different results from post hoc testing.

\section{Lactate concentration}

During the 30 minute walking tests, mean lactate concentration reached $1.1(0.2), 1.8(0.6)$, and $3.9(2.0) \mathrm{mmol} / \mathrm{l}$ at $\mathrm{V}_{70}$, $\mathrm{V}_{80}$, and $\mathrm{V}_{90}$ respectively. There was a significant effect of intensity on lactate between $V_{70}$ and $V_{80}$ as well as between $\mathrm{V}_{80}$ and $\mathrm{V}_{90}$ (fig 4).

\section{Energy consumption}

The total energy consumption during the 30 minute walking tests was $744(93) \mathrm{kJ}$ ( 177 (22) kcal or $5.2(0.7) \mathrm{MET}$ ) at $\mathrm{V}_{70}$, 930 (129) kJ (221 (31) kcal or 6.3 (2.5) MET) at $\mathrm{V}_{80}$, and 1224 (207) kJ (29l (49) kcal or 8.4 (1.4) MET) at $\mathrm{V}_{90}$. There was a significant effect of intensity $(\mathrm{p}<0.001)$.

\section{Catecholamine concentration}

The catecholamine concentrations did not differ significantly between the three intensity levels. After 30 minutes of 


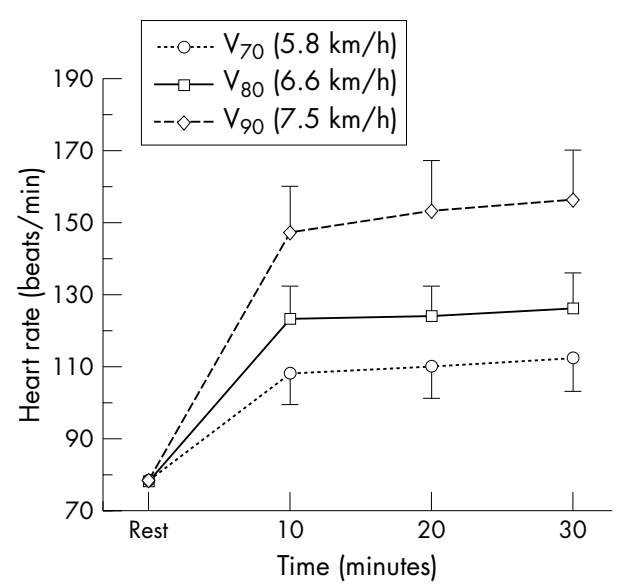

Figure 3 Heart rate during the 30 minute walking trials at $70 \%, 80 \%$, and $90 \%$ of the maximal velocity obtained in the incremental treadmill walking test $\left(V_{70}, V_{80}\right.$, and $\left.V_{90}\right)$. Values are mean $(S D)(n=16)$. All three values at each time point are significantly different from each other $(p<0.001)$.

walking, the mean maximal free noradrenaline concentrations were 6.48 (2.17), 5.47 (1.34), and 6.26 (1.76) nmol/l at $\mathrm{V}_{70}, \mathrm{~V}_{80}$, and $\mathrm{V}_{90}$ respectively. The corresponding adrenaline concentrations were $1.17(0.28), 1.00(0.27)$, and 1.10 (0.31) $\mathrm{nmol} / \mathrm{l}$.

\section{RPE}

A mean RPE of 10 (2) ("very easy" to "quite easy"), 12 (2) ("quite easy" to "a little difficult"), and 15 (2) ("difficult") was recorded at $\mathrm{V}_{70}, \mathrm{~V}_{80}$, and $\mathrm{V}_{90}$ respectively. There was a significant effect of intensity on RPE $(p<0.001)$. An RPE of 19 ("very, very difficult") was reported by one subject during $\mathrm{V}_{90}$. At the end of the endurance test, 12 subjects felt that walking at $\mathrm{V}_{80}$ was more comfortable than at $\mathrm{V}_{70}$ or $\mathrm{V}_{90}$.

\section{Complaints}

At $V_{90}, 12$ out of 16 subjects reported physical problems mainly in the lower legs. During $\mathrm{V}_{70}$ and $\mathrm{V}_{80}$, no problems were reported by the subjects.

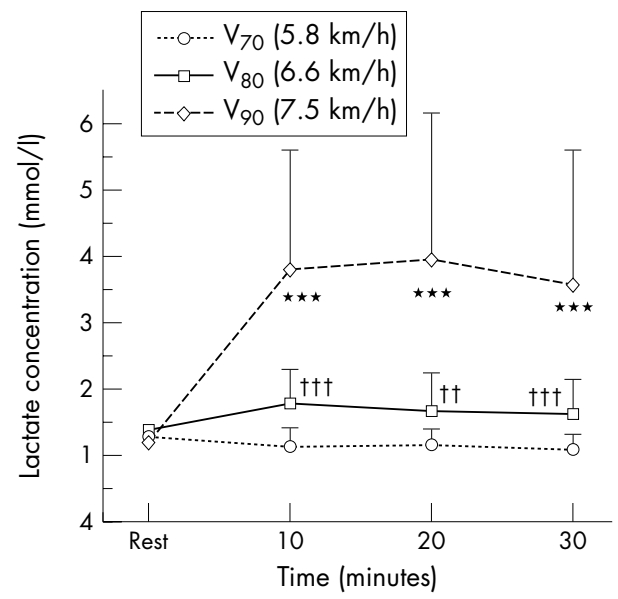

Figure 4 Lactate concentration during the 30 minute walking trials at $70 \%, 80 \%$, and $90 \%$ of the maximal velocity obtained in the incremental treadmill walking test $\left(\mathrm{V}_{70}, \mathrm{~V}_{80}\right.$, and $\left.\mathrm{V}_{90}\right)$. Values are mean (SD) ( $\mathrm{n}=$ 16). ***Significantly different from $V_{80}$ and $V_{70}(p<0.001)$, $†$, $† \dagger \dagger$ significantly different from $V_{70}(p<0.01, p<0.001$ respectively).

\section{DISCUSSION}

It has been shown that $\mathrm{VO}_{2}$ during $\mathrm{V}_{70}$ corresponds to the minimum intensity $\left(55 \% \mathrm{VO}_{2} \mathrm{MAX}\right)$ for training as recommended by ACSM, whereas $\mathrm{V}_{90}$ approaches the upper limit $\left(88 \% \mathrm{VO}_{2} \mathrm{MAX}\right){ }^{8}$ Thus, low intensity walking at $\mathrm{V}_{70}$ may lead to health benefits when it is performed frequently and for long enough. ${ }^{15}$ However, $\mathrm{V}_{80}\left(67 \%\right.$ of $\left.\mathrm{VO}_{2} \mathrm{MAX}\right)$ may be more appropriate for efficient endurance training. All subjects were above $60 \% \mathrm{VO}_{2} \mathrm{MAX}$ or $50 \% \mathrm{VO}_{2 \mathrm{R}}$ during $\mathrm{V}_{80}$. In contrast, $\mathrm{V}_{90}$ seems quite often to induce muscle pain in the lower legs even after only 30 minutes.

The mean maximal HR reached 220 minus age, indicating sufficient maximal effort on a treadmill. ${ }^{16}$ If the mean HR response of the three walking endurance exercises is considered, at $V_{70}$ the subjects are at the minimum HR, and at $\mathrm{V}_{80}$ and $\mathrm{V}_{90}$ they are within the recommended HR range. At $V_{80}$ and $V_{90}$, all subjects are above the minimum $H R$ described by ACSM. ${ }^{8}$

The mean lactate concentration during $\mathrm{V}_{70}$ was similar to resting concentrations, suggesting that the exercise intensity is low. During $\mathrm{V}_{90}$ the mean lactate concentration indicates intense physical performance. The mean lactate concentration during $\mathrm{V}_{80}$ was close to the IAT and within the range of extensive endurance training and ${ }^{17}$ and thus compatible with appropriate recreational intensity.

According to Morris and Hardman, ${ }^{3}$ in people with a body weight of about $70 \mathrm{~kg}$, the energy consumption during walking on even ground at a velocity of $6.4-8.0 \mathrm{~km} / \mathrm{h}$ corresponds to $25-36 \mathrm{~kJ} / \mathrm{min}$. In 40-56 year old men, Pollock et $\mathrm{al}^{7}$ measured an energy consumption of 28.3$36.5 \mathrm{~kJ} / \mathrm{min}$ for a velocity range of $6.8-7.6 \mathrm{~km} / \mathrm{h}$. The results of our study $(5.8-7.5 \mathrm{~km} / \mathrm{h}$ and $25-40 \mathrm{~kJ} / \mathrm{min})$ correspond well to these results.

The catecholamine concentrations did not differ significantly between intensities. Therefore this variable may not be suitable for defining efficient walking intensities. If the observed concentrations of noradrenaline and adrenaline are compared with those from earlier studies for cardiac patients during a strength endurance circuit and badminton training, they fall in the same range. ${ }^{18} 19$

Another variable that suggests that $\mathrm{V}_{80}$ is an adequate exercise intensity is the mean RPE (12 (2)). Dishman ${ }^{20}$ recommends the same RPE for endurance training with appropriate intensity. Spelman $e t a^{21}$ recommended an RPE of "quite easy" (Borg scale 11) for walking training with 50\%

\section{What is already known on this topic}

- Data on appropriate training intensities for walking vary in the literature, and published test procedures only partly allow training recommendations to be derived

- Approaches using an incremental treadmill walking test (ITWT) as the basis for individual training recommendations are rare

\section{What this study adds}

- An ITWT is applicable for deriving individual intensity recommendations for walking training

- The most promising intensity is $80 \%$ of the maximal velocity reached during ITWT 
of $\mathrm{VO}_{2} \mathrm{MAX}$. Also, the $70 \%$ walking endurance performance was subjectively perceived as too low ("very easy") and $\mathrm{V}_{90}$ was too intense and described as "very difficult".

Furthermore, orthopaedic problems occurred during the highest exercise intensity, mainly with pretibial muscles, as in earlier studies with recreational athletes. ${ }^{22}{ }^{23}$ Although symptoms in most cases disappeared quickly after exercise, straining beyond the pain limit should be avoided, as irreversible damage such as neurological disorders and muscle necroses has been described. ${ }^{24} 25$

In conclusion, an ITWT is appropriate for deriving individual intensity recommendations for walking training. The most promising intensity is $80 \%$ of the maximal velocity reached during ITWT.

\section{Authors' affiliations}

M Schwarz, L Schwarz, T Meyer, W Kindermann, Institute of Sports and Preventive Medicine, University of Saarland, Saarbrücken, Germany A Urhausen, Centre de l' Appareil Locomoteur, de Medicine du Sport et de Prévention, Luxembourg

Competing interests: none declared

\section{REFERENCES}

1 Duncan JJ, Gordon NF, Scott CB. Women walking for health and fitness. How much is enough? JAMA 1991;266:3295-9.

2 Manson JE, Greenland P, LaCroix AZ, et al. Walking compared with vigorous exercise for the prevention of cardiovascular events in woman. N Engl J Med 2002;347:716-25.

3 Morris JM, Hardman AE. Walking to health. Sports Med 1997;23:306-32.

4 Rippe JM, Ward A, Porcari DD, et al. Walking for health and fitness. JAMA 1988;259:2720-4.

5 Jefté M, Sidney K, Campbell J. Effects of a twelve-week walking program on maximal and sub maximal work output indices in sedentary middle-aged men and women. J Sport Med 1988;28:59-66.

6 Kline GM, Porcari JP, Hintermeister R, et al. Estimation of $\mathrm{VO}_{2 \max }$ from a onemile track walk, gender, age, and body weight. Med Sci Sports Exerc 1987; 19:253-9.
7 Pollock M, Caroll J, Graves J, et al. Injuries and adherence to walk/ jog and resistance training programs in the elderly. Med Sci Sports Exerc 1991;23:1194-1200.

8 American College of Sports Medicine. The recommended quantity and quality for exercise for developing and maintaining cardiorespiratory and muscular fitness, and flexibility in healthy adults. Med Sci Sports Exerc 1998;30:975-91.

9 Oja P, Laukkanen R, Pasanen M, et al. A 2-km walking test for assessing cardiorespiratory fitness in healthy adults. Int J Sports Med 1991;12:356-62.

10 Porcari JP, Ebbeling CB, Ward A, et al. Walking for exercise testing and training. Sports Med 1989;8:189-200.

11 Santiago M, Alexander J, Stull G, et al. Physiological responses of sedentary women to a 20 -week conditioning program of walking or jogging. Scand J Sports Sci 1987:9:33-9.

12 Hagberg JM, Coyle EF. Physiological determinants of endurance performance as studied in competitive race walkers. Med Sci Sports Exerc 1983;15:287-9.

13 Da Prada M, Zürcher G. Simultaneous radio enzymatic determination of plasma and tissue adrenaline, noradrenalin and dopamine within the femtomole range. Life Science 1976;19:1161-74.

14 Borg G. Psychophysical bases of perceived exertion. Med Sci Sports Exerc 1982; 14:377-81.

15 Blair SN, Kohl HW, Paffenbarger RS, et al. Physical fitness and all-cause mortality: a prospective study of healthy men and woman. JAMA 1989;262:2395-401.

16 Kindermann W. Recommendations for ergometry in medical practice. Disch Z Sportmed 1987;38:244-268.

17 Urhausen A, Coen B, Weiler B, et al. Individual anaerobic threshold and maximum lactate steady state. Int J Sports Med 1993;12:134-9.

18 Schwarz M, Urhausen A, Leukens S, et al. Cardio circulatory and metabolic strain in patients with coronary heart disease during Badminton as part of their ambulatory kinetotherapy. Int J Sports Med 1996;17(suppl 1):P8.

19 Urhausen A, Schwarz M, Stefan S, et al. Cardiovascular and metabolic strain during a strength-endurance circle training in out-patient cardiac rehabilitation. Dtsch Z Sportmed 2000;51:130-6.

20 Dishman RK. Prescribing exercise intensity for healthy adults using perceived exertion. Med Sci Sports Exerc 1994;29:1087-94.

21 Spelman CC, Russel R, Pate CA, et al. Self-selected exercise intensity of habitual walkers. Med Sci Sports Exerc 1993;25:1174-9.

22 Schwarz M, Schwarz L, Urhausen A, et al. Standards of sportsmedicine: walking. Disch Z Sportmed 2002;53:292-3.

23 Schwarz M, Schwarz L, Urhausen A, et al. Characteristic strain of walking as compared to jogging and cycle ergometry in persons with different aerobic performance capacity. Dtsch Z Sportmed 2001;52:136-41.

24 Lennart S, Forsberg A, Westlin N. Anterior tibial compartment pressure during race walking. Am J Sports Med 1986;2:136-8.

25 Logan JG, Rorabaeck Ch, Castle GS. The measurement of dynamic compartment pressure during exercise. Am J Med 1983;11:220-3. 